\title{
A evolução comparativa do orçamento público nos períodos de 2014 a 2016: estudo dasdespesas e receitas no poder público de Cerro Largo - RS
}

\section{The comparative evolution of the public budget in the periods from 2014 to 2016: study of dispenses and revenues in the public powers of Cerro Largo - RS}

\author{
Maikel Hanzen de Abertol \\ Universidade Regional Integrada do Alto Uruguai e das Missões \\ Brasil
}

Data da Submissão:09/05/2018

Data de aceite:13/06/2018

\section{RESUMO}

Este estudo objetivou analisar a evolução da previsão e realização das despesas e receitas do orçamento público no Poder Público de Cerro Largo no período de 2014 a 2016. Realizou-se uma pesquisa de natureza aplicada em determinado setor, de forma descritiva e qualitativa por meio de um estudo de caso no Poder Público Municipal. Nota-se que a receita tem aumentado no decorrer do período e as despesas também têm sidoelevadas, porém, o resultado mantémse instável, sendo quehouve superávits nos anos de 2016 e 2014 mais expressivos que em relação ao ano de 2015. A pesquisa contribui no sentido de verificar as diferenças na elaboração do orçamento público municipal, com vistas a acompanhar a evolução dos períodos e as relevantes alterações entre eles, para dessa forma planejar de forma mais correta os balanços anuais, bem como facilitar as decisões do gestor, através dos dados, na administração pública.

Palavras-chave: Receitas e despesas. Composição. Evolução. Administração Pública.

\begin{abstract}
This study aimed to analyze the evolution of the forecast and realization of the expenditures and revenues of the public budget in the Public Power of Cerro Largo in the period from 2014 to 2016. A research of an applied nature in a given sector was carried out in a descriptive and qualitative way through a case study in the Municipal Public Power. Note that revenue has increased over the period and expenses have also been raised, but the result remains unstable, with surpluses in the years 2016 and 2014 more significant than in relation to 2015 . The research contributes in order to verify the differences in the preparation of the municipal public budget, in order to monitor the evolution of the periods and the relevant changes between them, in order to better plan the annual balance sheets, as well as to facilitate the decisions of the manager, through public administration.
\end{abstract}

Keywords: Revenue and expenses. Composition. Evolution. Public administration. 


\section{INTRODUÇÃO}

A contabilidade pública trata do processo de planejamento e orçamento para dar suporte ao Poder Executivo, garantir o bem-estar da população e buscar uma ação planejada e transparente de governo. Dessa forma, é preciso uma administração transparente, para que assim se possa mostrar de onde os recursos foram retirados e qual é a destinação dada a eles (Brasil, 1964).

O orçamento público, um dos instrumentos mais importantes e antigos da administração pública, serve de base para que os governos organizem seus recursos financeiros. A Lei Complementar (LC) 101/2000, conhecida como Lei de Responsabilidade Fiscal (LRF), foca a melhoria da administração das contas públicas no Brasil, não havendo dúvida da importância do orçamento público para os Municípios, Estados e União.

O orçamento público é uma ferramenta importante para o funcionamento e a gestão do Município, porém a sua realização é feita basicamente para atender a legislação. Partindo da premissa da realização das receitas referente ao orçado, nota-se um déficit mediante o modelo de gestão.

A Lei de Responsabilidade Fiscal impôs compromissos com o orçamento público a todos os governantes e o cumprimento das metas fiscais, que devem ser prestadas e aprovadas pelo Poder Legislativo. A lei orçamentária fixa limites para despesas e estima receitas em mesmo grau, tendo por base metas para controlar receitas e despesas para que haja o equilíbrio das contas públicas.

Visando contribuir para a melhoria da gestão pública, em especial ao orçamento público, o presente estudo objetivou analisar a evolução das despesas programadas e realizadas, bem como as receitas previstas e realizadas, e a composição do orçamento público municipal no período de 2014 a 2016 no Poder Público de Cerro Largo.

O presente trabalho utilizou-se de pesquisa é descritiva, pois compreende informações que são caracterizadas, descritas e traçadas sobre o orçamento público. Sendo uma pesquisa qualitativa, que procura coletar, integrar e apresentar dados dos instrumentos públicos como fonte de evidência do estudo. Utiliza-se do estudo de caso, por levar em consideração a compreensão das receitas e despesas. Dessa forma, há a obtenção de uma descrição que almeja a compreensão completa do caso estudado. Foi feita uma análise documental com base nos instrumentos públicos, os quais são vistoriados juntamente à instituição, sendo esses instrumentos principalmente os orçamentos dos períodos citados.

O trabalho está estruturado da seguinte maneira: Inicialmente tem-se a introdução que 
apresenta os elementos que serão discorridos ao longo da produção, seguido do desenvolvimento que apresenta aspectos teórico-conceituais dos temais abordados no estudo, bem como, dados encontrados a partir da execução da pesquisa e, por fim, são tecidas as considerações finais que apresentam os elementos centrais debatidos ao longo do trabalho bem como os encaminhamentos do estudo.

\section{A CONTABILIDADE E O ORÇAMENTO PÚBLICO}

O objeto da contabilidade pública, segundo Rosa (2013), é o patrimônio público, entendido como um conjunto de bens e direitos, tangíveis ou intangíveis, onerosos ou não. Com o intuito de embasar a contabilidade pública, Andrade (2002) a relata como uma ciência capaz de registrar e controlar os atos e fatos seja econômicos ou administrativos referentes ao patrimônio público, de forma a possibilitar a geração de informações por meio da administração e seus usuários.

Lima e Castro (2000) acreditam que a contabilidade pública está voltada ao registro de previsão de receitas e fixação de despesas, à escrituração e ao acompanhamento da execução orçamentária, ao controle das operações de crédito, dívida ativa e obrigações do ente, apresentar as variações e o patrimônio e fornecer dados dobre os entes à contabilidade nacional.

Silva (2015) considera que a contabilidade pública deve ser um instrumento capaz de efetuar registro, controle, análise e interpretação dos atos e fatos da administração, para que dessas atividades os planejamentos e orçamentos sejam eficazes nas esferas públicas.

Sabendo da importância da contabilidade para a elaboração de demonstrações e levantamentos contábeis, nota-se que o profissional que atua na área, carrega com ele muitas responsabilidades. Com a autorização e diretrizes do gestor, é o contador público que elabora todos os planejamentos, bem como implantação de contas, contratos, prestação de contas, inscrição na dívida e todas as movimentações, sejam elas, patrimoniais, orçamentárias, financeiras ou compensatórias.

No que se refere ao planejamento orçamentário, Slomski (2003) destaca o seguinte:

Com base no plano plurianual o poder executivo elabora o projeto de Lei de Diretrizes Orçamentárias, com vista na elaboração da Lei do Orçamento para o ano seguinte, e o encaminha para o Poder Legislativo que o apreciará e votará, até meados do ano, antes do recesso parlamentar de julho, devolvendo-o para o Poder Executivo, para a elaboração da referida Lei do Orçamento para o exercício financeiro seguinte (SLOMSKI, 2003, p. 304). 
Acerca disso compreende-se a necessidade de seguir uma ordem de apresentação e execução dos instrumentos previstos em lei, de forma a cumprir os prazos instituídos. Assim a Lei Orçamentária Anual é elaborada conforme o Plano Plurianual e a Lei de Diretrizes Orçamentárias.

De acordo com a Resolução 1.133/08 (NBC T 16.6), são no balanço orçamentário que se encontram evidenciadas as receitas e as despesas orçamentárias, em níveis relevantes de análise, e em confronto com o orçamento inicial e suas alterações com a execução, demonstrando o resultado orçamentário.

Para Kohama (2014), o Plano Plurianual (PPA) é um plano de médio prazo, de quatro anos, no qual se procura ordenar as ações do governo para serem atingidos os objetivos e metas fixados para um período de quatro anos, em nível de governo federal, estadual ou municipal.

A Lei de Diretrizes Orçamentárias (LDO) tem como finalidade direcionar a elaboração do orçamento anual, composto de orçamento fiscal, do orçamento de investimento das empresas e do orçamento da seguridade social, de forma a equipará-los com o disposto nas diretrizes, objetivos e metas da administração pública estabelecidos no PPA (KOHAMA, 2014).

$\mathrm{O}$ orçamento anual visa à concretização do planejado no PPA, obedecendo também a LDO, e nele são programadas as ações a serem executadas para alcançar os objetivos determinados (KOHAMA, 2014).

A Lei 4.320/64 dispõe que os créditos suplementares e especiais deverão ser autorizados por Lei e abertos por Decreto do Poder Executivo. A abertura depende da existência de recursos disponíveis para ocorrer à despesa e será justificada.

Os créditos especiais e extraordinários terão vigência no exercício financeiro em que forem autorizados, salvo se a autorização for promulgada nos últimos quatro meses do exercício, de acordo com o parágrafo $2^{\circ}$, do art. 167 , da CF.

Para Kohama (2014), o orçamento público é uma análise da situação atual para identificar as ações ou as alterações a serem desenvolvidas, visando atingir a situação desejada, projetando-se para o futuro o que se pretende alcançar em curto, médio e longos prazos.

De acordo com Castro (2013), “Os princípios orçamentários são regras fixadas em legislação, ou formas utilizadas e aceitas historicamente, com vistas a dar estabilidade, consistência e transparência às ações públicas" (CASTRO, 2013, p. 39). 
A Lei 4.320/64 estabeleceu vários princípios do orçamento, dentre eles: o princípio da anualidade e periodicidade, da clareza, da especificação ou discriminação, da exclusividade, da não afetação ou não vinculação das receitas, da prévia autorização ou legalidade, da publicidade, da unidade, da universalidade, do equilíbrio, da exatidão, da flexibilidade, da programação, da regionalização, da unidade da tesouraria ou unidade de caixa e do orçamento bruto.

\subsection{RECEITAS E DESPESAS}

As receitas são, no que diz respeito às finanças públicas, entradas ou ingressos designados pelos cofres públicos, inclusive variações ativas a receber, no momento da ocorrência do fato gerador. São quaisquer contratos ou títulos de que derivem direitos em favor do Estado, às receitas então irão aumentar o patrimônio (KOHAMA, 2014).

O art. 11 da Lei 4.320/1964 classifica as receitas orçamentárias em receitas correntes e de capital. As receitas correntes, segundo Silva (2015), são subdivididas em: tributária, de contribuições, patrimonial, agropecuária, industrial, serviços, transferências correntes e outras receitas correntes. E as receitas de capital são: operações de crédito, alienação de bens, amortização de empréstimos, transferências de capital e outras receitas de capital (SILVA, 2015).

Despesas públicas, segundo Kohama (2014), são gastos fixados na lei orçamentária ou em leis especiais, destinados à execução dos serviços públicos e aumentos patrimoniais, bem como à satisfação dos compromissos da dívida pública e, ainda, à restituição ou pagamento de importâncias recebidas a título de cauções, depósitos, consignações outros.

O art. 12 da Lei 4.320/64 classifica a despesa pública em despesas correntes e de capital. As despesas correntes são despesas que visam manter o funcionamento dos órgãos e serviços públicos sendo subdivididas, segundo Silva (2015), em: pessoal e encargos sociais, juros e encargos da dívida, transferências correntes, outras despesas correntes. E as despesas de capital são os gastos realizados com o objetivo de adquirir e aumentar o patrimônio da administração pública, subdivididos em: investimentos, inversões financeiras, amortização da dívida e as transferências de capital (SILVA, 2015).

\section{A EVOLUÇÃO ORÇAMENTÁRIA E SEUS PRINCIPAIS COMPONENTES}

O trabalho surge através de uma pesquisa realizada no ambito do executivo no Poder 
Público de Cerro Largo, os elementos utilizados para a pesquisa foram os orçamentos públicos, bem como resultados de entrevistas junto à contadora. Dessa forma pode-se perceber as variações entre as receitas e despesas, bem como entender o que compõe cada recurso através da natureza das operações.

A evolução dos itens do orçamento público se dá, analisando o que foi previsto e realizado, quando se trata de receitas e o que foi programado e realizado, quando se refere às despesas. Há também a disposição dos principais componentes do orçamento, juntamente com a sua destinação, para melhor entender cada aplicação, cabe lembrar que esses se baseiam nos períodos de 2014, 2015 e 2016.

\subsection{EVOLUÇÃO DAS RECEITAS CORRENTES}

A previsão das receitas correntes tem sido aumentada no decorrer dos períodos e, da mesma forma, o recebimento também tem sido maior a cada ano. Essa comparação é realizada através da previsão inicial e a realização das receitas, apresentados no gráfico, conforme

\section{Gráfico 1:}

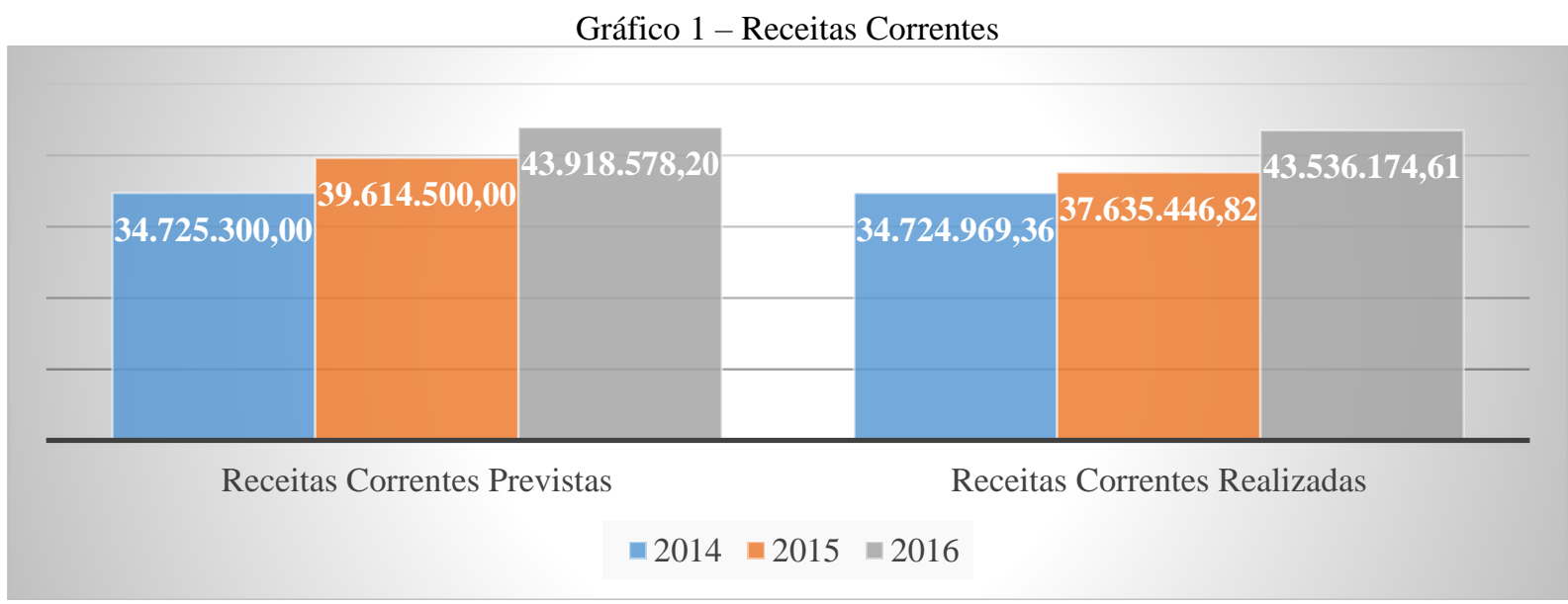

Fonte: sistematizado pelo autor a partir dos orçamentos do poder Público de Cerro Largo

Em 2014 apenas R\$ 330,64 não foram realizados, conforme previsto, mas houve bastante variações negativas nas receitas tributárias, onde estava previsto maior arrecadação com impostos, e nas transferências correntes, onde houve menos transferências efetuadas pela União, perante o que se esperava. Porém quando se trata das receitas patrimoniais, estava previsto arrecadação inferior dos recursos da previdência, houve, portanto, maior realização. 
No ano de 2015, houve arrecadação menor que o previsto, sendo uma diferença de receitas correntes de $\mathrm{R} \$ 1.979 .053,18$, onde as transferências correntes foram às principais responsáveis por essa variação, sendo um total de $\mathrm{R}$ 2.669.003,91 menos arrecadados do que estava previsto.

A maior diferença do previsto e arrecadado em 2016, é referente ao valor menor que o previsto das transferências correntes de $\mathrm{R} \$ 2.202 .042,85$, porém uma arrecadação superior de $\mathrm{R} \$$ 1.845.858,05, também houve diferença positiva referente às outras transferências correntes, que são as restituições, e negativa relativo às receitas tributárias.

\subsubsection{PRINCIPAIS COMPONENTES}

Fazendo parte das receitas correntes, as receitas tributárias dividem-se em impostos, taxas e contribuições de melhorias, os mesmos possuem deduções, principalmente devido a descontos. As receitas tributárias sofreram algumas oscilações, principalmente no ano de 2015, que vem a ser o ano com menor rendimento, pois no mesmo ano houve deduções, que são referentes a descontos no IPTU e nas taxas de prestação de serviço que são os casos de recolhimento do lixo, as contribuições de melhoria referem a valores arrecadados para manutenção e reforma de ruas. O maior rendimento dos períodos foi em 2016, que teve $39,62 \%$ sobre o total de receitas tributárias dos três períodos. Desses valores os mais relevantes são os impostos, que em equivale a 78,73\% em 2014, 78,04 \% em 2015 e 81,15\% em 2016, ou seja, o último período estudado apresenta a maior variação e recebimento de impostos.

Os impostos como o IPTU e o IRRF são corrigidos anualmente de acordo com decreto instituído pelo gestor do município, sendo que o Imposto sobre Propriedade Territorial Urbana, no município de Cerro Largo, é atualizado anualmente de acordo com o Índice Geral de Preços de Mercado (IGPM), assim percebe-se uma maior arrecadação em cada um dos períodos referente a esses impostos. O ITBI atingiu uma arrecadação elevada em 2016, devido ao alto volume de transferências de bens imóveis. E o ISSQN houve uma maior arrecadação desde a instalação da Universidade Federal da Fronteira Sul (UFFS), devido os serviços nela inclusos, como limpeza e vigilância, terem obrigação de recolhimento, e o aumento também segundo a LC 116/03, que atribui a cobrança de ISSQN aos registros públicos, cartorários e notariais.

O Poder Público de Cerro Largo obtém receita através de contribuições sociais e econômicas, sendo estas principalmente relativas a contribuições de previdenciários e para 
pagamento de iluminação pública, arrecadadas a partir da conta de luz mensal, e repassadas ao município. Em 2016 notou-se o maior vulto de receita de contribuições referente aos anos anteriores, e esse aumento se deve às contribuições previdenciárias de servidores ativos, que em 2016 foi de $\mathrm{R} \$ 1.220 .206,89$ e em 2014 foi $\mathrm{R} \$ 896.872,03$. A arrecadação das contribuições econômicas se dá pela contribuição para custeio da iluminação pública, valor esse que é recolhido dos contribuintes para servir de custeamento de gastos com iluminação de ruas e parques públicos. Esse valor tem sido arrecadado mais a cada período, sendo que foram realizados $\mathrm{R} \$ 133.161,71$ a mais em 2016 que em 2014.

As receitas patrimoniais, sendo elas referente a valores de dívidas em valores imobiliários, remuneração por depósitos bancários e investimentos do Recurso Próprio de Previdência Social (RPPS). As receitas mais relevantes são em investimento do RPPS, que foram de $\mathrm{R} \$ 2.071 .565,86$ em 2014, $\mathrm{R} \$ 2.387 .303,58$ em 2015 e de $\mathrm{R} \$ 3.666 .151,16$ em 2016. Em compensação os depósitos bancários em sua remuneração tiveram maior recebimento no ano de 2015, os dividendos permanecem estáveis nos três períodos estudados. Dessa forma o total de receitas patrimoniais em 2016 foi maior, sendo 31,74\% maior que em 2015, e 40,65\% maior que em 2014.

As receitas agropecuárias são os menores valores arrecadados pelo Poder Público de Cerro Largo. Estas tiveram previsão de entrada de $\mathrm{R} \$ 20.000,00$ em cada ano, porém apenas em 2014 houve realização em um valor de R \$465,00, apenas 2,32\% do valor esperado. Há também as receitas industriais, que compõe as receitas correntes, sendo que essas não houve realização em nenhum dos anos de 2014, 2015 e 2016.

As receitas de serviços são subdivididas em serviços administrativos, de captação, adução, tratamento, reservação e distribuição da água e os demais serviços. Em 2014 obtiveram valores referentes a concurso público, o que em 2015 e 2016 não houve, esse é o principal motivo da receita total de serviços ser mais elevada em 2014. Referente à captação e distribuição da água, houve apenas $\mathrm{R} \$ 15.371,12$, enquanto em 2015 houve $\mathrm{R} \$ 37.899,96$. Porém, esse valor vem sendo maior no serviço de ligação de água e esgoto, mas devido ao concurso realizado em 2014, esta vem a ser a maior receita entre os períodos.

As transferências correntes efetuadas ao Município estudado tanto pela União, Estado e pelo Fundo de Manutenção e Desenvolvimento da Educação (FUNDEB), dividem-se principalmente em:

a) As transferências da União em sua grande maioria são provenientes do Fundo de Participação dos Municípios, então esse valor equivale a 76,97\% em 2014 sobre o total de transferências da União, em 2015 a 81,74\% e em 2016 a 80,69\%. 
b) As transferências do Estado são provenientes em sua grande maioria da cota-parte do ICMS. Essas transferências são de $25 \%$ sobre a circulação de mercadoria para o território de origem e tem aumentado anualmente conforme o valor das mercadorias aumenta, principalmente devido à inflação. A cota-parte do ICMS representa 77,78\%, 78,02\% e 78,24\% do total das transferências do Estado, respectivos aos anos de 2014, 2015 e 2016.

c) E as transferências do FUNDEB são os valores recebidos do Fundo, transferidos e a sua perda, o que totaliza $\mathrm{R} \$ 8.043 .187,44, \mathrm{R} \$ 8.595 .659,80$ e $\mathrm{R} \$ 9.173 .487,28$ em 2014, 2015 e 2016, respectivamente. As perdas reduziram notoriamente em 2016, devido ao número de matrículas acrescidas em escolas municipais.

As outras receitas correntes são arrecadações com base em multas, juros, a dívida ativa e indenizações e restituições. No que diz respeito a multas e juros, são mais relevantes no que diz respeito à dívida ativa, sendo que essa representa 95,63\%, 97,84\% e 96,13\%, nos anos de 2014, 2015 e 2016. Também compõem as outras receitas correntes as restituições e indenizações, que são as principais fontes de arrecadação dessa natureza, e as receitas da dívida ativa, que se divide em tributária e não tributária, sendo que em 2015 a receita da dívida ativa tributária foi à maior registrada desses períodos, totalizando $\mathrm{R} \$ 569.303,20$.

\subsection{RECEITAS DE CAPITAL}

As receitas de capital são as transferências ao Município feitas pela União e Estados. As previsões são inferiores à sua realização, sendo que a maior realização ocorre em 2015, quando a previsão é menor. E a menor realização é em 2016, quando a previsão inicial foi maior, isso se dá devido às transferências de capital de 2016 serem bastante inferiores às arrecadações dos demais períodos da pesquisa. Segue os dados dos anos de 2014, 2015 e 2016 no Gráfico 2:

Gráfico 2 - Receitas de Capital

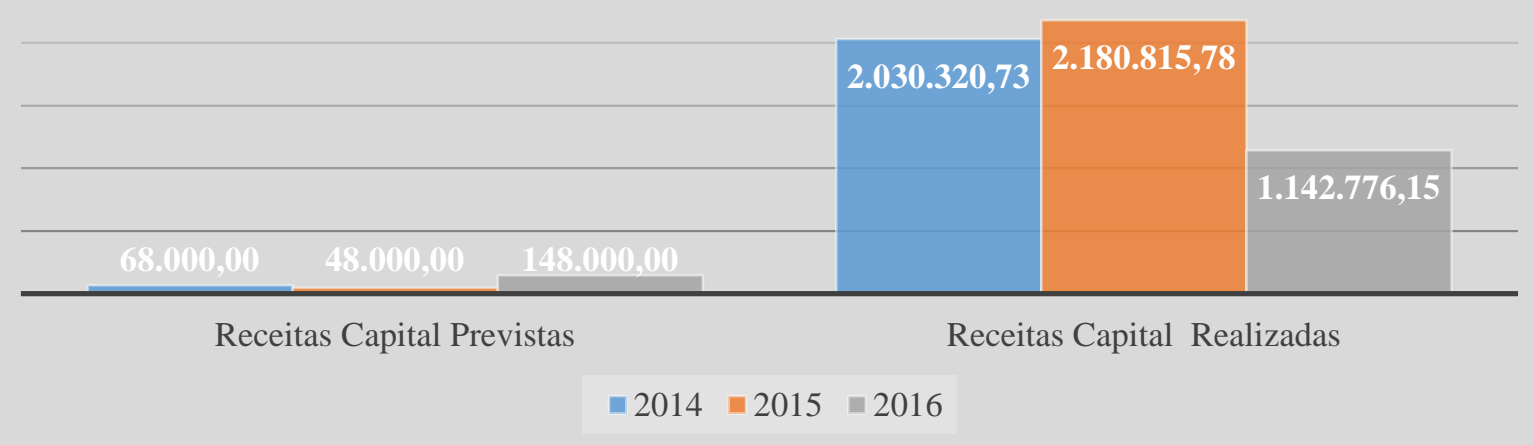


Fonte: sistematizado pelo autor a partir dos orçamentos do poder Público de Cerro Largo

As previsões das receitas de capital são em valores bastante inferiores, principalmente quando se trata das transferências de capital, valores esses que não podem ser previstos, devido à incapacidade de o planejamento compreender quanto será repassado pela União ao Município.

As receitas de capital têm envolvimento direto com o patrimônio da entidade, assim buscou-se analisar os três anos estudados e comparados os valores arrecadados. Dessa forma, uma de suas subdivisões é a receita com operações de crédito, que são aplicações em programas, esses valores são decorrentes de programas que visam o benefício do Município.

As receitas de operação de crédito internas referem-se ao financiamento para obras de infraestrutura junto à Comunidade Habitacional da Vila São José, onde sua maior realização foi em 2015, com o valor de $\mathrm{R} \$ 436.402,24$.

A alienação de bens é a receita por meio do qual há venda de bens. No caso houve apenas em 2016, o valor de $\mathrm{R} \$ 62.450,00$, referente à venda de bens inservíveis constante no patrimônio da entidade, o qual gera uma receita de ganho sobre o mesmo.

As receitas com a amortização de empréstimos, ou seja, os valores concedidos aos contribuintes e para crédito educativo. As receitas com financiamento e amortização de empréstimos tiveram seu maior rendimento em 2015 , no valor de $\mathrm{R} \$ 27.457,30$, e o menor em 2015, com o valor de $\mathrm{R} \$ 18.651,86$.

As receitas com transferências de capital são divididas entre transferências da União e dos convênios, são valores provindos da União e convênios, sendo que apenas em 2014 houve transferência para o programa de educação, no entanto houve transferências de convênios da União de altos valores, sendo que em 2014 foi de R\$1.664.876,66, em 2015 de $\mathrm{R} \$ 1.716 .956,24$ e em 2016 de R\$948.593,01.

As transferências de convênios são valores para investimentos em despesas de capital, ou seja, gastos a serem realizados para obras e equipamentos para benefício da sociedade.

\subsection{RECEITA CORRENTE INTRAORÇAMENTÁRIA}

As receitas correntes intraorçamentárias estão demonstradas equiparando os devidos períodos de acordo com a previsão inicial e a realização das receitas, o que segue no

Gráfico 3: 
Gráfico 3 - Receita Corrente Intraorçamentária

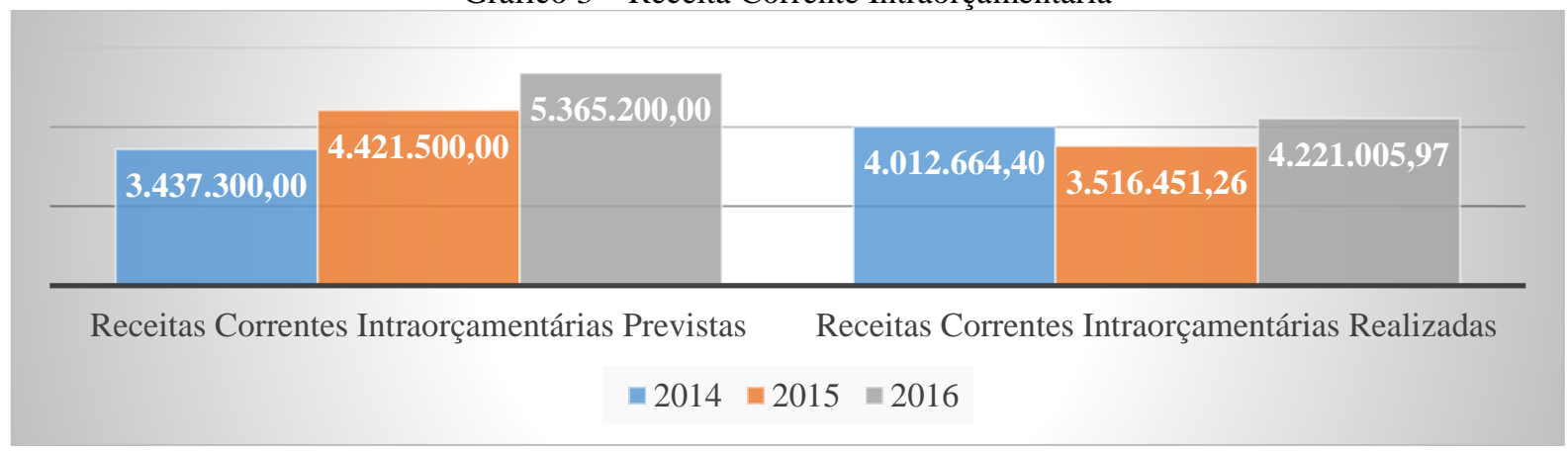

Fonte: sistematizado pelo autor a partir dos orçamentos do poder Público de Cerro Largo

A previsão de receitas correntes intraorçamentárias vem sendo a cada ano maior, porém a sua realização tem se mantido estável, sendo que em 2015 foi à menor arrecadação e em 2016 a maior. Essas receitas foram previstas com o aumento padrão nos períodos de 2014, 2015 e 2016, sendo que no ano de 2015, a realização dessas são as menores entres as pesquisadas, devido ao fato da redução de arrecadação das contribuições patronais do pessoal ativo e referente aos valores para amortização do déficit atuarial, relativo aos investimentos da previdência.

As receitas intraorçamentárias são os valores arrecadados com as contribuições à previdência, são referentes às cobranças de contribuição patronal do servidor e da previdência, sendo que o total das receitas de 2014, 2015 e 2016, foi de, respectivamente, $\mathrm{R} \$ 4.012 .664,40, \mathrm{R} \$ 3.516 .451,26$ e $\mathrm{R} \$ 4.221 .005,97$.

A contribuição patronal de servidor inativo foi igual a $\mathrm{R} \$ 0,00$ nos períodos estudados. Referente ao servidor ativo o maior valor encontra-se no ano de 2016 , que corresponde a $\mathrm{R} \$$ $1.465 .585,56$.

A contribuição previdenciária para amortização do déficit atuarial é a diferença entre os compromissos líquidos e os ativos financeiros garantidores do sistema de previdência já capitalizados. Apresentavam maior valor em 2014, que correspondia R $\$ 3.054 .706,74$, e o menor valor em 2015, de R \$2.708.875,96.

\subsection{DEDUÇÕES DAS RECEITAS}

As deduções da receita são previstas a um valor superior à sua realização, porém segue uma linha tênue de aumento no decorrer dos anos, tanto na previsão quando na sua realização. Conforme apresentado no gráfico abaixo, 
Gráfico 4, as deduções das receitas são previstas com valores bastante próximos à sua realização:

Gráfico 4 - Deduções da Receita

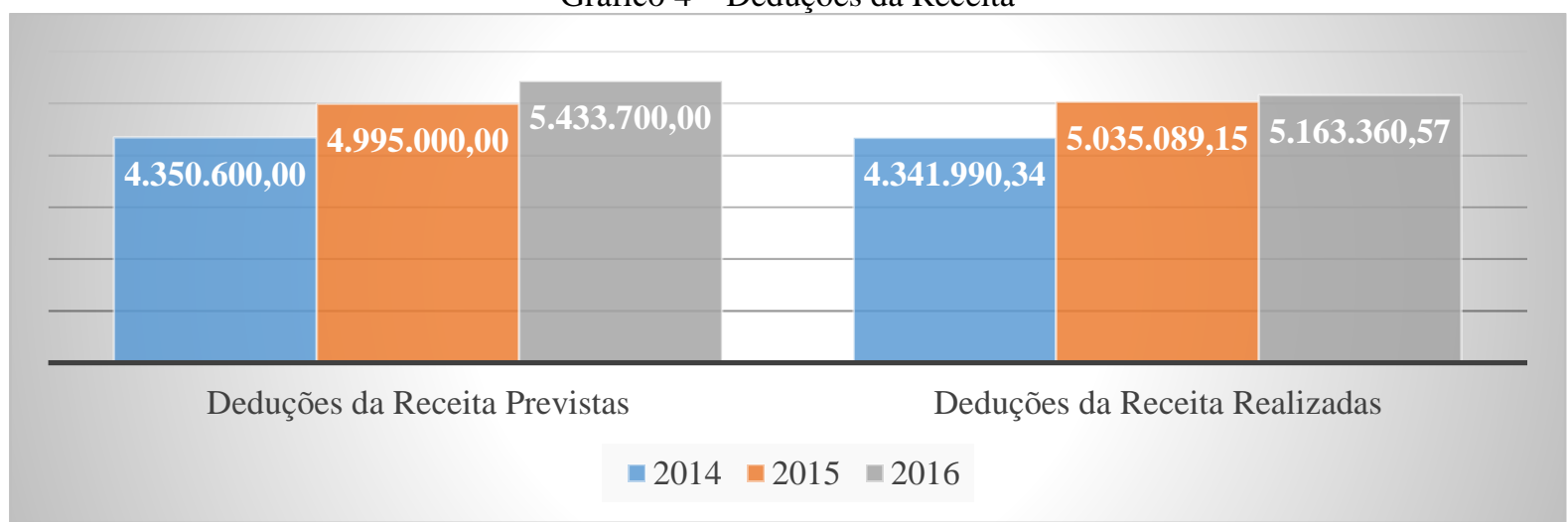

Fonte: sistematizado pelo autor a partir dos orçamentos do poder Público de Cerro Largo

Nos anos de 2014 e 2016, foram deduzidos valores inferiores aos previstos, isso é referente a menores descontos aos contribuintes, enquanto no ano de 2015 houve descontos superiores. Esses descontos se dão devido à necessidade de haver maior arrecadação com o pagamento de impostos pelos cidadãos, isso é uma atração para efetuar a liquidação de tributos em atraso pela sociedade.

As deduções são valores abatidos das receitas, em sua grande maioria refletem aos descontos ao FUNDED, renúncia, restituição e descontos concedidos. As deduções para formação do FUNDEB são valores a partir das cotas-parte e transferências financeiras, dentre essas as que mais se destacam é a cota-parte do ICMS, gerando uma dedução de R\$ 1.698.238,69 em 2014, de $\mathrm{R} \$ 1.851 .102,22$ em 2015 e de $\mathrm{R} \$ 1.842 .645,20$ em 2016; e a cotaparte do FPM, com seus valores de $\mathrm{R} \$ 2.014 .810,73$, $\mathrm{R} \$ 2.117 .767,87$ e $\mathrm{R} \$ 2.420 .872,46$, respectivamente nos anos de 2014, 2015 e 2016.

As deduções por renúncia, que são as cobranças indevidas lançadas, que de acordo com a CF em seu art. 150, é vedado à instituição de impostos a templos de qualquer custo, partidos políticos, entidades sindicais dos trabalhadores, instituições de educação e de assistência social, sem fins lucrativos, apresentam pequenos valores compostos por IPTU próprio, Manutenção e Desenvolvimento do Ensino (MDE) e Ações e Serviços Públicos de Saúde (ASPS), composto também pelas taxas de limpeza pública.

As restituições então apresentam valores referentes aos impostos e rendimentos por programas do Município, dentre esses os serviços de pavimentação e de passe livre estudantil, sendo que esses valores representam o total de $0,53 \%, 0,48 \%$ e $0,27 \%$, nos anos de 2014 , 2015 e 2016, respectivamente, tendo por base o valor total das deduções. 
Os descontos concedidos estão em sua grande maioria ligados aos impostos, taxas e multas, gerando uma dedução elevada, principalmente no que trata o IPTU e as taxas de lixo. Assim, percebe-se que o ano de 2016 foi quando houve a maior dedução comparando aos demais períodos.

\subsection{DESPESAS CORRENTES}

As despesas correntes programadas são maiores do que as realizadas, bem como os gastos vêm aumentando no decorrer dos anos. Porém, deve-se levar em consideração que se tem a inflação em cada período, o que influi na variação do nível de gastos.

As despesas correntes têm sofrido um aumento durante os períodos estudados, conforme apresentado na Gráfico 5:

Gráfico 5 - Despesas Correntes

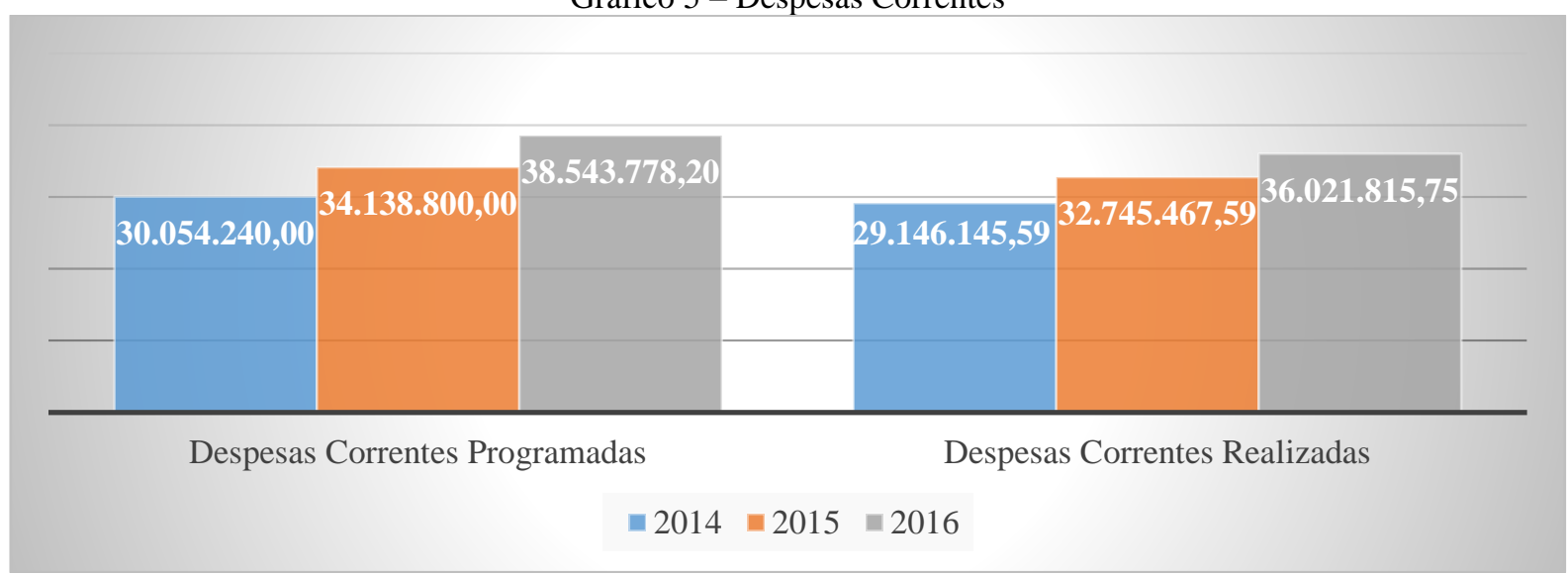

Fonte: sistematizado pelo autor a partir dos orçamentos do poder Público de Cerro Largo

A menor diferença da arrecadação perante a programação está no ano de 2015, quando os gastos com as vantagens do pessoal ativo têm menor variação. Sendo que os valores mais relevantes das despesas correntes estão nas despesas com pessoal e encargos.

No ano de 2014, foram arrecadados $\mathrm{R} \$ 908.094,41$ menos que o programado, onde as maiores diferenças são com pessoal, referente ao pessoal ativo, e as outras despesas correntes, relativo aos serviços prestados por outras pessoas jurídicas e materiais de consumo.

As diferenças mais relevantes no ano de 2015 são no que diz respeito, as outras despesas correntes. Em 2016, a maior diferença é referente ao pessoal e encargos sociais, sendo um valor de $\mathrm{R} \$ 1.920 .962,45$.

As despesas com pessoal e seus encargos são os gastos necessários para manter o funcionamento e o atendimento aos quesitos básicos de um ente. Gastos esses relativos a 
transferências a instituições privadas sem fins lucrativos e demais aplicações diretas e intraorçamentárias.

Os gastos com pessoal e encargos sociais nas transferências a instituições privadas sem fins lucrativos tem-se mantido constante, havendo queda um pouco maior de 2015 para 2016, no valor de $\mathrm{R} \$ 76.863,55$. As vantagens fixas de pessoal civil reduzem $\mathrm{R} \$ 104.844,74$ e ocorreu um aumento nas obrigações patronais em $\mathrm{R} \$ 27.981,19$.

Nas despesas diretas com pessoal há maiores desembolsos em aposentadoria e em vantagens fixas do pessoal civil; sendo que as vantagens fixas equivalem a 50,35\% em 2014, $50,12 \%$ em 2015 e 53,95\% em 2016, referente à receita total com pessoal e encargos sociais.

As pensões têm um aumento de $\mathrm{R} \$ 160.853,15$ em 2016, se comparados ao ano de 2014, e o contrato por tempo determinado, que são aqueles que equivalem ao pessoal contratado pelo ente para exercer funções em determinado período aumentou $R \$ 316.638,77$, em 2016, referente a 2014, enquanto esse valor houve uma queda se comparados 2014 e 2015, sendo um total de $\mathrm{R} \$ 50.485,48$ gastos menos em 2015.

As obrigações patronais em aplicações diretas intraorçamentárias equivalem em 2014 a $\mathrm{R} \$ 3.764 .087,66$, em 2015 a $\mathrm{R} \$ 4.574 .927,91$ e em 2016 a $\mathrm{R} \$ 3.165 .717,41$, sendo esses valores elevados se tratando de intraorçamentárias.

As despesas com juros e encargos da dívida estão relacionadas à dívida por contrato de financiamento realizado pelo ente. Os desembolsos com juros e encargos da dívida referem-se aos juros pagos pela aquisição do financiamento para pavimentação da Vila São José. Os pagamentos ocorreram apenas em 2015 e 2016, pelo fato de 2014 e parte de 2015 estar dentro do prazo de carência para o pagamento das prestações. Nota-se que o que alavanca esse valor para $\mathrm{R} \$ 74.999,22$ em 2016são os encargos sobre a dívida por contrato não apresentadas em 2015.

\subsection{DESPESAS DE CAPITAL}

De acordo com o Gráfico 6, nota-se que há bastante discrepância entre os valores programados e os realizados, assim como houve a redução desses gastos em cada um dos exercícios: 


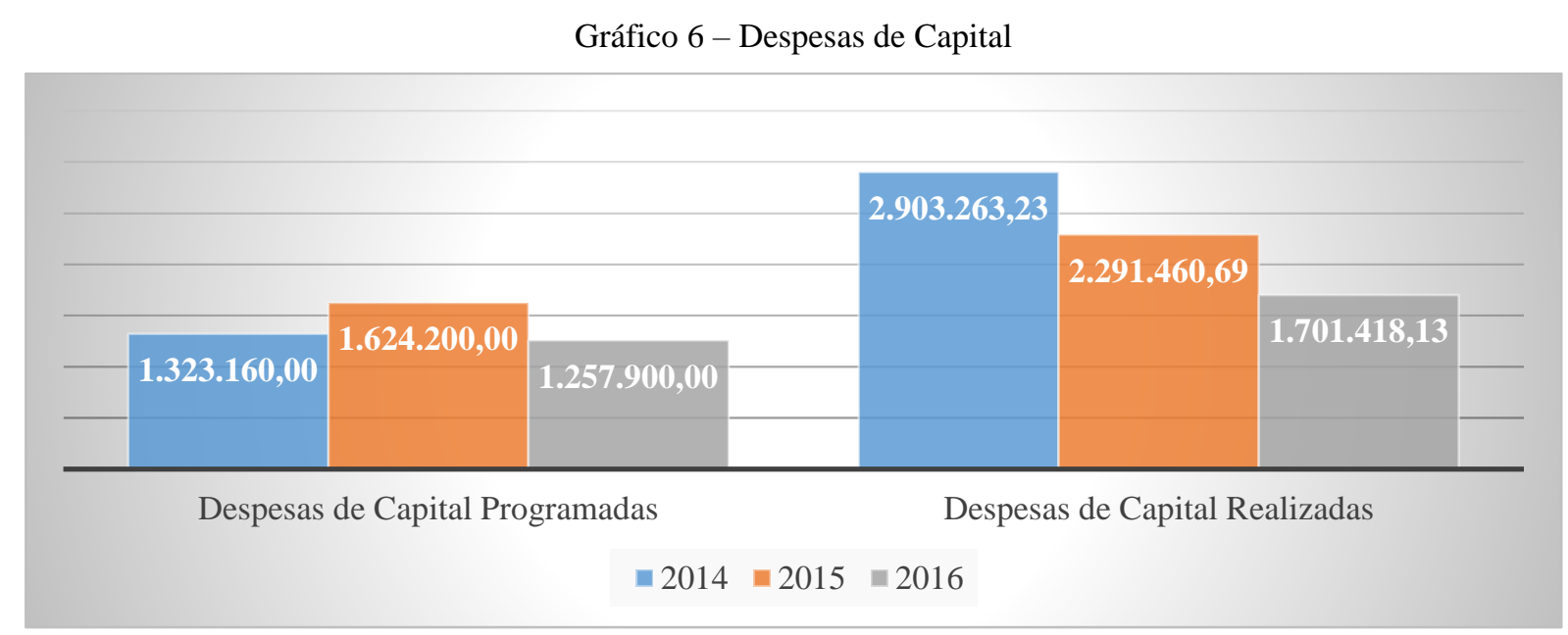

Fonte: sistematizado pelo autor a partir dos orçamentos do poder Público de Cerro Largo

Nos períodos pesquisados, houve maior realização referente ao que estava programado. No ano de 2014 , foi realizada $\mathrm{R} \$ 1.580 .103,23$ além do previsto, principalmente pelo fato de haver investimentos em obras e equipamentos para suprir as necessidades no Município.

As reduções da realização das despesas de capital foram devidas a diminuição de investimentos posteriores ao ano de 2014. Em 2015 reduziu principalmente gastos com equipamentos e materiais permanentes ao Município, e no ano de 2016, a redução mais relevante foi referente à construção do patrimônio público, com obras e instalações.

Quando se trata se outras despesas correntes, é importante salientar que correspondem às transferências à União e ao Estado, essas transferências ocorrem devido ao valor que o Município deve repassar. Em relação ao Estado (transferências aos Estados e DF) e também em relação à Federação (transferências à União), essas transferências são compostas também por valores às instituições privadas sem fins lucrativos, multinacionais e outras aplicações diretas.

As outras despesas correntes obtêm maior vulto monetário nas aplicações diretas em ambos os exercícios, chegando a representar 92,35\% em 2014, 93,65\% em 2015 e 94,55\% em 2016, referente às outras despesas correntes totais.

Os outros serviços de terceiros como Pessoa Jurídica (PJ) têm-se um valor bastante representativo chegando a um gasto de $\mathrm{R} \$ 5.323 .593,00$ em 2016, quando em 2014 era de $\mathrm{R} \$$ 4.154.209,48, equivale um aumento de 21,96\%. O custo do poder público também é bastante relevante, bem como o material para uso e consumo do Poder Público, previamente 
empenhados.

As despesas com investimento são as transferências da União e dos Estados, e aplicações diretas, com intuito de investir no capital do Município. Das despesas com investimentos, são das despesas de capitais as que apresentam valor mais alto perante as outras, e essas despesas vêm reduzindo desde 2014, quando eram $\mathrm{R} \$ 2.883 .075,28$, para $\mathrm{R} \$ 2.221 .929,58$ em 2015 e, posteriormente, para $\mathrm{R} \$ 1.614 .837,57$ em 2016, onde de 2015 para 2016 houve uma redução de $\mathrm{R} \$ 607.092,01$.

Dentre as despesas de investimentos mais relevantes estão às aplicações diretas, onde se trata de investimentos em obras e instalações e outros equipamentos permanentes à entidade. O gasto com obras e instalações foi maior em 2014, quando correspondia a $\mathrm{R} \$$ 1.759.437,58, e o mesmo ano foi o que mais houve gastos em equipamentos e materiais permanentes.

As inversões financeiras são provenientes das concessões de empréstimos e financiamentos, com isso notou-se que em 2014 o valor era de $\mathrm{R} \$ 10.699,92$ e passou para $\mathrm{R} \$ 6.303,12$ em 2015, sendo que em 2016 nenhum valor foi registrado.

As despesas com a amortização da dívida são os valores que foram gastos para pagamento de parcelas e quitação da dívida em contrato. Os desembolsos para amortização da dívida foram crescendo gradativamente no que diz ao principal da dívida no contrato, porém referente ao principal da dívida por contrato resgatado nota-se que foi registrado valor apenas em 2016, que seria $\mathrm{R} \$ 39.160,12$.

As reservas de contingência têm sido programadas com uma elevação a cada período, porém em nenhum dos períodos estudados houve sua realização, por não haver necessidade da criação de reservas. As previsões das receitas foram alcançadas, e suficientemente, para cobrir exatamente os valores repassados à previdência própria.

As reservas de contingências são valores que durante o ano, poderá haver a falta, podendo assim ser efetuados esses gastos para a suplementação, principalmente quando há uma necessidade de repor fatores devidos a previdência. Isso se dá porque todas as receitas previstas deverão ser iguais à programação das despesas.

\subsection{RESULTADOS DOS PERÍODOS}

Cada período pode gerar informações como déficit e superávit. De acordo com a Tabela , estão dispostos os valores dos resultados dos períodos de 2014, 2015 e 2016 : 
Tabela 1 - Resultados dos Períodos

\begin{tabular}{l|r|r|r}
\hline \multicolumn{1}{c|}{ Contas } & \multicolumn{1}{c|}{2014} & \multicolumn{1}{c}{2015} & 2016 \\
\hline 1- Receitas & $\mathrm{R} \$ 36.425 .964,36$ & $\mathrm{R} \$ 38.297 .624,71$ & $\mathrm{R} \$ 43.736 .596,16$ \\
\hline Receitas Correntes & $\mathrm{R} \$ 34.724 .969,36$ & $\mathrm{R} \$ 37.635 .446,82$ & $\mathrm{R} \$ 43.536 .174,61$ \\
\hline Receitas de Capital & $\mathrm{R} \$ 2.030 .320,73$ & $\mathrm{R} \$ 2.180 .815,78$ & $\mathrm{R} \$ 1.142 .776,15$ \\
\hline Receitas Intraorçamentárias & $\mathrm{R} \$ 4.012 .664,40$ & $\mathrm{R} \$ 3.516 .451,26$ & $\mathrm{R} \$ 4.221 .005,97$ \\
\hline (-) Deduções & $\mathrm{R} \$ 4.341 .990,13$ & $\mathrm{R} \$ 5.035 .089,15$ & $\mathrm{R} \$ 5.163 .360,57$ \\
\hline 2- Despesas & $\mathrm{R} \$ 32.049 .408,82$ & $\mathrm{R} \$ 35.036 .958,28$ & $\mathrm{R} \$ 37.723 .233,88$ \\
\hline Despesas Correntes & $\mathrm{R} \$ 29.146 .145,59$ & $\mathrm{R} \$ 32.745 .467,59$ & $\mathrm{R} \$ 36.021 .815,75$ \\
\hline Despesas de Capital & $\mathrm{R} \$ 2.903 .263,23$ & $\mathrm{R} \$ 2.291 .490,69$ & $\mathrm{R} \$ 1.701 .418,13$ \\
\hline Déficit ou Superávit & $\mathbf{R} \$ \mathbf{4 . 3 7 6 . 5 5 5 , 5 4}$ & $\mathbf{R} \mathbf{3 . 2 6 0 . 6 6 6 , 4 3}$ & $\mathbf{R} \mathbf{6 . 0 1 3 . 3 6 2 , 2 8}$ \\
\hline
\end{tabular}

Fonte: sistematizado pelo autor a partir dos orçamentos do poder Público de Cerro Largo

Os valores positivos de arrecadação do Poder Público são os superávits. Dessa forma, nota-se que todos os períodos estudados têm valores positivos. Esses são aplicados em depósitos bancários do próprio poder público, atribuindo-os ao patrimônio municipal. Assim, em 2016 houve o maior resultado dos períodos estudados, ou seja, $\mathrm{R} \$ 6.013 .362,27$, o que equivale a $13,75 \%$ do valor total das receitas.

O período em que houve menor arrecadação referente aos gastos foi o ano de 2015, onde o valor do resultado foi $\mathrm{R} \$ 3.260 .666,43$, o que equivale a $45,78 \%$, menos que no período posterior e $25,5 \%$ menor que o resultado do ano anterior.

As altas variações orçamentárias podem ocorrer, segundo Pignata e Carvalho (2015), pelo fato de a crise de 2015, que ocorreu principalmente pela má administração do governo, que por falta de planejamento, necessitaram aumentar tributos, causando assim um freio na economia. A previsão de déficits e não pagamento de juros, fez com que não houvesse mais investimentos nas notas de créditos do Brasil.

Foi a partir dessa crise que se notou uma menor arrecadação no período de 2015, embora houvesse o aumento de receita, as despesas aumentaram em maior grau, levando assim a um menor superávit.

\section{CONCLUSÃo}

Partindo da análise entre os períodos, o qual foi realizado por meio dos demonstrativos contábeis do Município de Cerro Largo, conclui-se que o Município está em condição 
favorável devido à apresentação de superávit nos períodos estudados. Esse também apresentou acréscimo na arrecadação da receita nos anos estudados e as despesas aumentaram quase na mesma proporção. Essa instabilidade pode configurar uma situação de preocupação no decorrer dos anos, se este resultado continuar a persistir, pois no ano de 2015 o resultado foi menor que o ano anterior e o posterior.

As despesas correntes são as que mais se destacam em relação às despesas de capital, sendo que as despesas com pessoal e encargos são as mais significativas, pois se percebe que o Município em estudo está com o quadro de funcionários completo, com aumento das despesas a cada ano estudado, sendo necessário que seja feito um estudo dos gastos com pessoal para dessa forma que os limites impostos pela Lei de Responsabilidade Fiscal sejam comprometidos, principalmente, para que não faltem recursos para prestar serviços e atender os requisitos básicos demandados pela população.

Destaca-se a importância da contabilidade pública na geração de informações aos servidores, à Administração e ao cidadão que participa da gestão pública, mesmo que de forma indireta. Percebe-se que os contadores se tornam cada vez mais importantes na administração pública, pois são eles quem tem conhecimentos referentes à dimensão da responsabilidade de um ente público e é com sua ajuda que o gestor deverá se orientar e planejar, para tomar decisões. É o contador quem está diretamente relacionado com a correta arrecadação e aplicação dos recursos públicos, mantendo a transparência.

Os cidadãos deveriam adquirir interesse em apropriar-se de conhecimentos referentes à prestação de contas, fiscalizando se os recursos estão sendo aplicados de maneira correta, com vistas a atender às necessidades da população, cumprindo com o papel de controle social. Para essa maior participação, é necessário dispor da importância dos cidadãos na ajuda e participação no orçamento público.

A reforma previdenciária, conforme a proposta de emenda à constituição, bastante debatidos, também afetaria o setor público, assim aumentaria o período de contribuição dos servidores públicos, reduzindo o número de aposentados e gastos com os mesmos. Da mesma forma, haveria um maior superávit nos períodos posteriores. Lembrando que havendo essa aprovação traria insatisfação por meio dos servidores, portanto, a reforma necessitaria sofrer alguns ajustes para que essa não prejudique os cidadãos e, ao mesmo tempo, contribuísse para a recuperação das contas públicas. 


\section{REFERÊNCIAS}

ANDRADE, Nilton de Aquino. Contabilidade Pública na Gestão Municipal- Novos métodos após a LC n. 101/00 e as classificações contábeis advindas da SOF e STN. São Paulo: Atlas, 2002.

BRASIL. Constituição (1988). Constituição da República Federativa do Brasil. Poder Legislativo, Brasília,

DF. Disponível em: <http://www.planalto.gov.br/ccivil_03/constituicao/ConstituicaoCompilado.htm>. Acesso em: 01/08/2017.

BRASIL. Lei Complementar 101, de 04 de maio de 2000. Poder Legislativo, Brasília, DF. Disponível em:<http://www.planalto.gov.br/ccivil_03/leis/LCP/Lcp101.htm>. Acesso em: 08/08/2017.

BRASIL. Lei no 4.320 de 17 março de 1964. Brasília, DF. Disponível em:〈http://www.planalto.gov.br/ccivil_03/leis/L4320.htm>. Acesso em: 15/08/2017.

CASTRO, Domingos Poubel de. Auditoria, Contabilidade e Controle Interno no Setor Público. São Paulo: Atlas, 2013.

CONSELHO FEDERAL DA CONTABILIDADE. Resolução n. 1.133/08: Aprova a NBC T 16.6 - Demonstrações Contábeis. Disponível em: <http://portalcfc.org.br/wordpress/wpcontent/uploads/2013/01/Setor_P\%C3\%BAblico.pdf>. Acesso em: 04/10/2017

KOHAMA, Heilio. Contabilidade Pública. 14. ed. São Paulo: Atlas, 2014.

LIMA, Diana Vaz de; CASTRO, Róbison Gonçalves de. Contabilidade Pública. São Paulo: Atlas, 2000.

PIGNATA, Francine A.; CARVALHO, Daltro O. Efeitos da crise econômica no Brasil em 2015. Revista Eletrônica "Diálogos Acadêmicos" (ISSN: 0486-6266), 2016.

ROSA, Maria Berenice. Contabilidade do Setor Público. 2. ed. São Paulo: Atlas, 2013.

SILVA, José Antônio da. Série Provas \& Concursos - Contabilidade Pública. Método, 2015.

SLOMSKI, Valmor. Manual de Contabilidade Pública. 2. ed. São Paulo: Atlas, 2003. 